\title{
Comparison Of Imagery From A Scanning And A Pushbroom Microwave Radiometer
}

\author{
Skou, Niels; Kristensen, Steen Savstrup
}

Published in:

International Geoscience and Remote Sensing Symposium

Publication date:

1991

Document Version

Publisher's PDF, also known as Version of record

Link back to DTU Orbit

Citation (APA):

Skou, N., \& Kristensen, S. S. (1991). Comparison Of Imagery From A Scanning And A Pushbroom Microwave Radiometer. In International Geoscience and Remote Sensing Symposium (Vol. Volume 4, pp. 2107-2110). IEEE.

\section{General rights}

Copyright and moral rights for the publications made accessible in the public portal are retained by the authors and/or other copyright owners and it is a condition of accessing publications that users recognise and abide by the legal requirements associated with these rights.

- Users may download and print one copy of any publication from the public portal for the purpose of private study or research.

- You may not further distribute the material or use it for any profit-making activity or commercial gain

- You may freely distribute the URL identifying the publication in the public portal

If you believe that this document breaches copyright please contact us providing details, and we will remove access to the work immediately and investigate your claim 


\title{
COMPARISON OF IMAGERY FROM A SCANNING AND A PUSHBROOM MICROWAVE RADIOMETER
}

\author{
Niels Skou \& Steen Savstrup Kristensen
}

\author{
Electromagnetics Institute, Building 348, \\ Technical University of Denmark, \\ DK2800 Lyngby
}

\begin{abstract}
The pushbroom radiometer principle has been conceived in order to avoid the mechanical scanning traditionally used in imaging microwave radiometer systems. But does a real life pushbroom radiometer actually work as predicted, producing imagery as we are used to see it from a scanner? To answer this question a 21 channel, $36.5 \mathrm{GHz}$ pushbroom radiometer intended for airborne use has been designed and built. Both this instrument and a $34 \mathrm{GHz}$ mechanically scanned radiometer were flown over a test area in Denmark. Data from the two different instruments has been transformed into false colour imagery. and compared.
\end{abstract}

Keywords: pushbroom, radiometer, microwave.

\section{INTRODUCTION}

A traditional microwave radiometer system creates imagery by mechanically scanning the antenna in such a way that the footprint covers a certain swath consecutively. Apart from mechanical complications (especially cumbersome for space borne instruments) this method leads to a relatively short dwell time per foot print, hence short integration time and poor sensitivity. In a pushbroom radiometer a host of radiometers connected to a multibeam antenna simultaneously covers the swath. No problems with a mechanically scanned antenna are present and the dwell time per footprint is relatively large leading to potentially good sensitivity [1].

After initial studies in the mid 80'es [2] a $36.5 \mathrm{GHz}$ demonstration model for airborne use was built by Matra [3] and delivered to ESTEC (European Space and Technology Centre of the European Space Agency) primo 1990. The purpose of this demonstration model is to assess some of the technological problems associated with the pushbroom principle, and also to demonstrate that the pushbroom radiometer, when operated from a proper platform (in this case an aircraft), does give a brightness temperature image of the sensed area comparable to that from a traditional scanner.
This paper describes the demonstration flights carried out on the 6'th of November 1990 using a C-130 aircraft of the Royal Danish Air Force. First the TUD (Technical University of Denmark) scanning, multifrequency radiometer system TUDRAD was flown over a characteristic landscape in Denmark, and on a second flight the pushbroom radiometer was flown over the same area. Comparisons are made between the pushbroom imagery and the imagery from the 34 GHz channel of the TUD scanner.

\section{DESCRIPTION OF THE RADIOMETER SYSTEMS TUDRAD}

The TUD radiometer system employ receivers at 5, 17 , and $34 \mathrm{GHz}$. All three radiometers are essentially identical and operate according to the noise-injection principle. The antenna is based on a $1 \mathrm{~m}$ aperture offset parabolic reflector scanning sinusoidally around a vertical axis and illuminated by $3 \mathrm{mi}$ crowave horns pointing upwards along that very axis. The system can be configurated for vertical or horizontal polarization (individually for each channel).

The palletized antenna is mounted on the ramp of the C-130, the ramp is closed during take-off and transit but lowered to its horizontal position when measurements are to be carried out. The ground speed of the aircraft is 140 knots $(=70 \mathrm{~m} / \mathrm{sec})$ during operation with the ramp open.

The radiometer system is designed to give contiguous coverage over a swath of $2000 \mathrm{~m}$ when flying at an altitude of $2000 \mathrm{~m}$ with a speed of $70 \mathrm{~m} / \mathrm{sec}$. This results in a minimum dwell time per footprint at 34 $\mathrm{GHz}$ of $15.6 \mathrm{msec}$ and the radiometers use $8 \mathrm{msec}$ integration and sampling time thus being on the safe side from an aliasing point-of-view.

As already mentioned the antenna (with the radiometer receivers) is pallet mounted and positioned on the loading ramp of the C-130 aircraft. Further inside the aircraft is found the operators console also mounted on a pallet. This console includes the digital processing and control unit and the CCT recorders. The processing and control unit is connected with the Inertial Navigation System (INS) of the aircraft and navigation information is recorded on the CCT along with measured radiometric data. 
In Table 1 the main characteristics of the radiometer system, as configurated for the present task, are given. Note, that the $5 \mathrm{GHz}$ channel is omitted as it was not mounted for the present task. Its footprint is so coarse that it was deemed of no value for comparison with the pushbroom instrument.

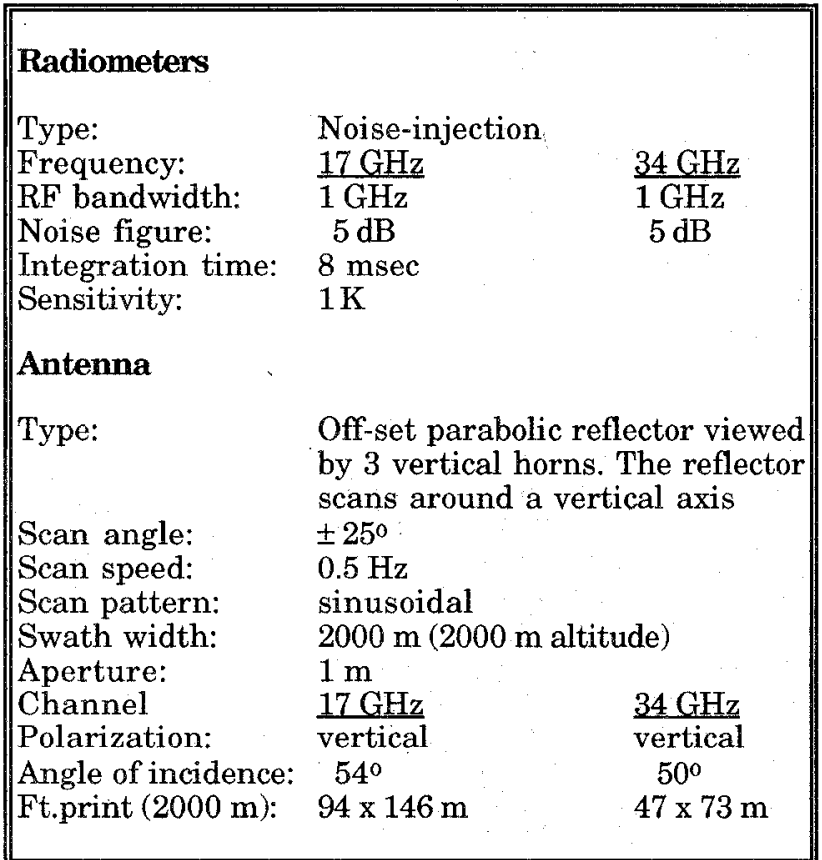

Table 1: TUDRAD, main characteristics

\section{PUSHBROOM}

The pushbroom concept is illustrated in Figure 1. In the pushbroom radiometer system a multiple beam antenna covers the swath while the platform (be it an aircraft or a spacecraft) moves forward. A host of radiometer receivers are connected to an equal number of antenna feeds producing individual beams to sense the Earth simultaneously.

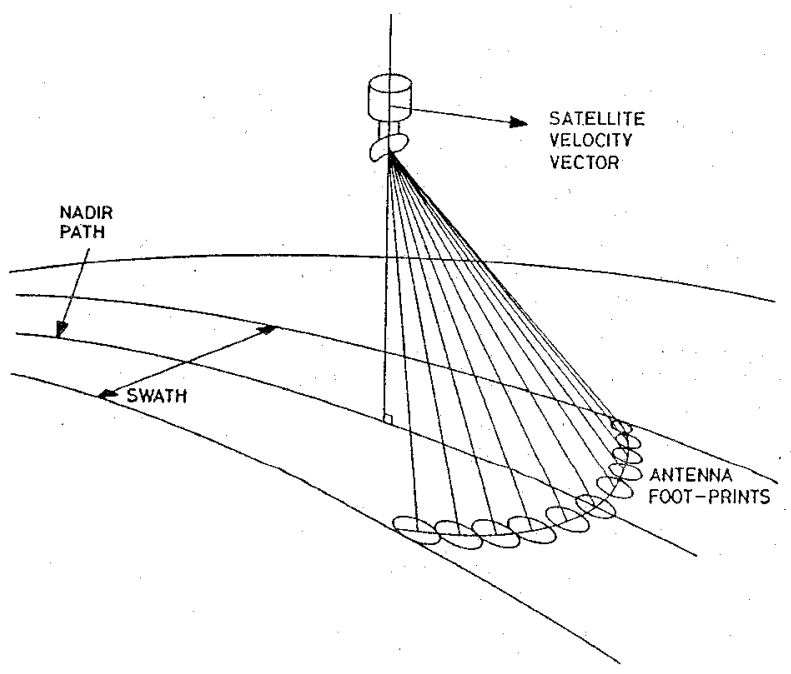

Figure 1: Pushbroom imager
Earth surface observation systems normally require that the antenna beam be scanned around a vertical axis (conical scan with fixed incidence angle on the ground). This applies to the present case, and the word "scan" will be used also in conjunction with the pushbroom concept although no movement is involved. For Earth observation systems half-scan angles up to $60^{\circ}$ are often desired; here a $\pm 25^{\circ}$ scan is employed. For this reason it is considered necessary that the reflector be made rotationally symmetric around a vertical axis. This is obtained by the socalled torus antenna in which the reflector surface is generated by rotating a section of a parabolic arc around an oblique axis.

It is necessary to get contiguous ground coverage in the across track direction, and at the same time the horns need be large enough to give a proper illumination of the reflector. These requirements lead to congestion along the focal circle of the reflector, and it is necessary to use two rows of feed horns as indicated in Figure 2.

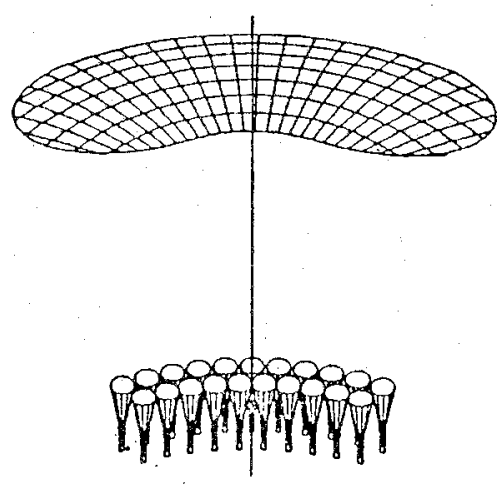

Figure 2: Antenna reflector and feed horns

From an antenna point of view this is perfectly OK as the displacements from the "correct" positions are small relative to the focal length, but it causes beam squinting and hence deviations of $\pm 1.7^{\circ}$ from nominal incidence angle.

The torus reflector is a silver coated carbon fibre structure; the 21 feed horns are dual mode smooth conical horns. The radiometer system employs 21 identical total power receivers. A $1 \mathrm{kHz}$ square wave modulated internally generated noise can be injected simultaneously in all channels at certain time intervals. Knowing the amplitude of this modulated noise the gain of the channels can be determined. Offsets between the channels are taken care of during the data treatment by integrating in the along track direction data taken over a relatively long sea scene. Improper balance between channels will give a banding effect in the image and the integrated data values will give a calibration error vector that can be used to adjust the data from nearby scenes.

The data recording system for the pushbroom radiometer is a standard $\mathrm{PC}$ and the data is recorded on the hard disc.

The radiometer system is built to be mounted on a C130 pallet and flown just like the TUD radiometer system. 
The main characteristics of the pushbroom radiometer are shown in Table 2.

\begin{tabular}{||ll||}
\hline Radiometer type: & total power with noise adding \\
& gain calibration \\
Frequency: & $36.5 \mathrm{GHz}$ \\
RF bandwidth: & $1 \mathrm{GHz}$ \\
Integration time: & $25 \mathrm{msec}$ \\
Sensitivity: & $0.5 \mathrm{~K}$ \\
Antenna type: & Off-set parabolic torus reflector \\
& viewed by 21 feed horns \\
"Scan" angle: & $\pm 25^{\circ}$ \\
Swath width: & $1000 \mathrm{~m}(1000 \mathrm{~m}$ altitude $)$ \\
Aperture: & $33 \mathrm{~cm}$ \\
Polarization: & vertical \\
Angle of inc.: & $50^{\circ}\left(48.3^{\circ}\right.$ and $51.7^{\circ}$ for the two \\
& rows $)$ \\
Footprint $(1000 \mathrm{~m}):$ & $45 \times 70 \mathrm{~m}$ \\
&
\end{tabular}

Table 2: Pushbroom, main characteristics THE DEMO FLIGHIS

On 6 'th November 1990 two flights were carried out over Stavns fjord in Denmark containing many small islands. The first flight took the TUD scanning radiometer over the test area around 11.00 local time, while the second flight brought the pushbroom instrument over the same area 3 hours later. On each flight 4 passes were made over the test area.

The weather was perfect with clear skies, sunshine, low winds, and a temperature of around $5^{\circ} \mathrm{C}$.

Due to the clear weather, navigation accuracy could be checked easily, and it was obvious that all passes were performed with good precision. Hence, the swath of the pushbroom radiometer was well within the swath of the scanning radiometer on comparable passes.

\section{THE IMAGERY}

Figure 3 shows an example of the imagery created by the pushbroom radiometer. The same flight track is shown 3 times with different levels of data correction carried out. The brightness temperature range is from $150 \mathrm{~K}$ (black) to $200 \mathrm{~K}$ (white) in order to enhance calibration problems in the sea signatures (temperature values around $185 \mathrm{~K}$ ).

The bottom track shows "raw" data where the digital counts from each of the 21 channels merely have been transformed into brightness temperatures based on hot and cold load calibrations performed just before take-off. The image is clearly dominated by the errors caused by the beam squinting not yet corrected for. The $+/-1.7^{\circ}$ will give a difference of some $8 \mathrm{~K}$ between even and uneven channels according to sea models. The 21 dark patches lying in arc shaped patterns with regular intervals in the flight direction results from the internal gain calibration procedure in the instrument during which it cannot measure the antenna temperature. They also indicate the relative position of the boresight for the different antenna beams.
The middle track shows the result after a $+/-4 \mathrm{~K}$ beam squint compensation over the sea. The remaining errors are due to instrument drifts since the calibration was carried out about two hours earlier. This is taken care of by along track integration over the open sea further down the track (to the right of the scene displayed in Figure 3) as described earlier. The result is shown as the top image in the figure, and satisfactory inter-channel calibration is now obtained: over a presumed homogeneous area the 21 channels read values with a standard deviation of $0.62 \mathrm{~K}$.

In Figure 4 are finally compared a pushbroom image of the test area (top) with the $34 \mathrm{GHz}$ scanner image (mid) and the $17 \mathrm{GHz}$ scanner image (bottom). The pushbroom image has been corrected as described above. The brightness temperature range is now from $150 \mathrm{~K}$ (black) to $275 \mathrm{~K}$ (white); n. b. the present black and white reproduction reveals the image information very poorly compared with the false colour imagery discussed during the conference! It is obvious that there is no great difference in image quality when comparing the pushbroom and the 34 $\mathrm{GHz}$ scanner results.

\section{CONCLUSIONS}

A 21 channel pushbroom radiometer has been flown over a test area in conjunction with a comparable frequency mechanically scanned radiometer in such a way that ground resolutions for the two instruments were alike and direct comparison of output imagery is possible. Indeed, the pushbroom instrument produces an image just like we are used to see it from a scanner. Hence, the pushbroom concept can be regarded as ready for future applications where mechanical scanning is undesired. It is noted that calibration of the many channels is somewhat more cumbersome than is the case for the single channel scanner, and further work is ongoing.

\section{ACKNOWLEDGEMENT}

The pushbroom work has been carried out under ESTEC contracts with D. Maccoll as monitor.

The antenna design was carried out by TICRA with K. Pontoppidan as driving force.

The demonstration model was built by MATRA with B. Le Stradic and D. Scournec as key persons.

These gentlemen have contributed greatly to the development of the pushbroom concept.

\section{REFERENCES}

[1] N. Skou: "Microwave Radiometer Systems: Design \& Analysis”, Artech House, 1989.

[2] N. Skou: "Pushbroom Microwave Radiometer Systems for Space Applications", IGARSS'85, pp 641-46.

[3] B. Le Stradic: "Design, Manufacture and Test of a Demo Model Pushbroom Radiometer", in "Microwave Radiometry and Remote Sensing Appl.”, ed. P. Pampaloni, VSP, 1989, pp 315-20. 


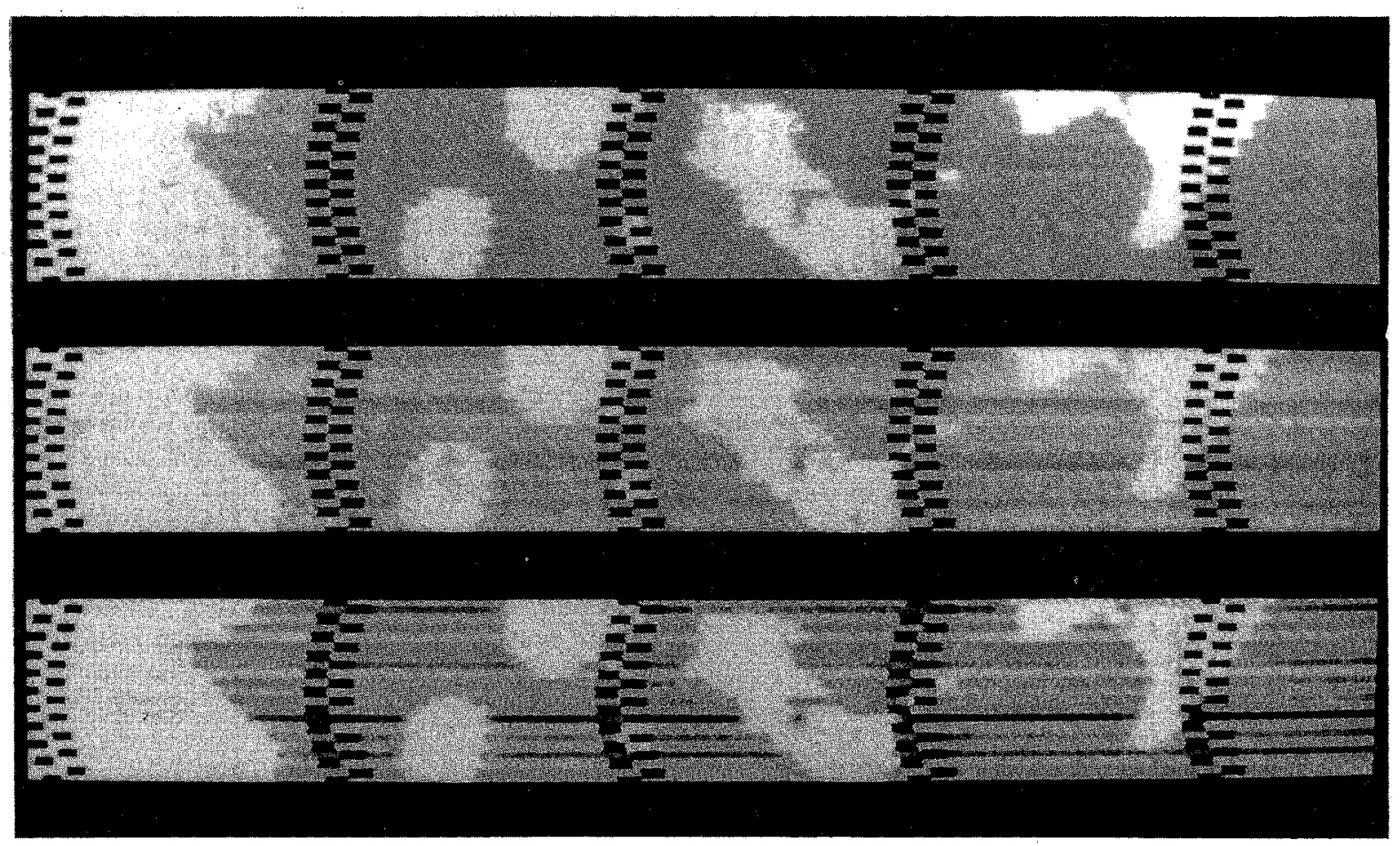

Figure 3: Pushbroom imagery; bot: raw data, mid: squint corrected, top: gain corrected

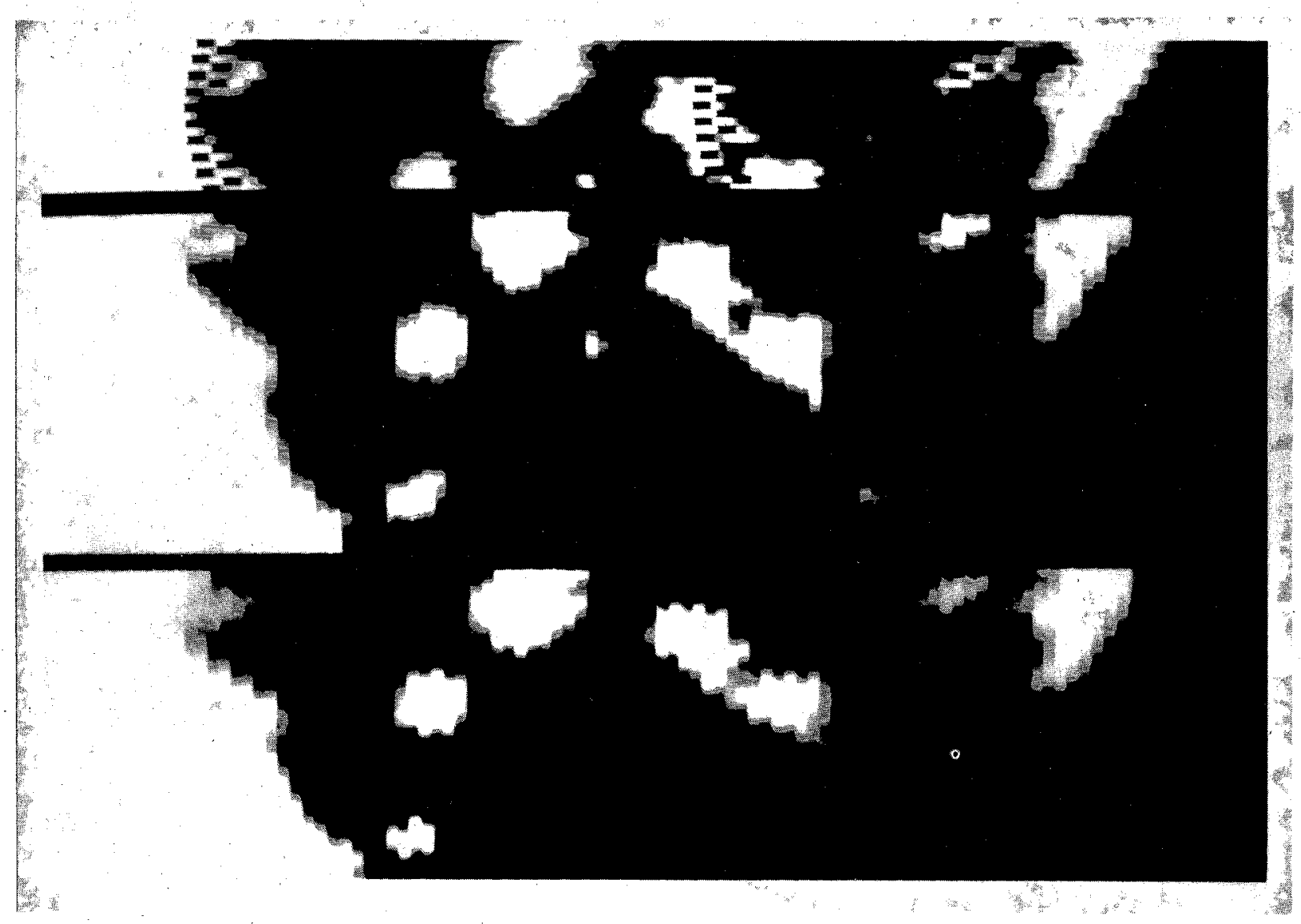

Figure 4: Imagery; top: pushbroom, mid: $34 \mathrm{GHz}$ scanner, bot: $17 \mathrm{GHz}$ scanner 